\title{
Alfabetização científica em espaços não formais de ensino e de aprendizagem
}

\section{Scientific literacy in non-formal spaces for teaching and learning}

\author{
${ }^{1}$ Simone Beatriz Reckziegel Henckes \\ ${ }^{1}$ Andreia Aparecida Guimarães Strohschoen aaguim@univates.br
}

\section{RESUMO}

A presente pesquisa possibilitou discussão acerca de dois temas que, através da divulgação científica mostraram-se foco de estudos no campo do Ensino e da Educação, a Alfabetização Científica (AC) e os Espaços Não Formais de Ensino e de Aprendizagem (ENF). O objetivo deste estudo perpassa em analisar como professores da Educação Infantil, dos Anos Iniciais e Anos Finais do Ensino Fundamental utilizam os ENF buscando a AC de seus alunos, em quatro escolas públicas do estado do Rio Grande do Sul/Brasil. Os procedimentos metodológicos envolveram pesquisa descritiva e exploratória, de cunho qualitativo, utilizando o método indutivo. Os sujeitos investigados foram oito professoras - duas da Educação Infantil, três dos Anos Iniciais e três Anos Finais do Ensino Fundamental, de quatro escolas do município de XX. A coleta dos dados foi contemplada em 2018 e contou com entrevistas semiestruturadas, observações registradas no diário de campo e realização de roda de conversa. Os dados foram analisados realizando-se Análise Textual Discursiva, gerando categorias emergentes. Os professores demonstraram desconhecer os termos AC e ENF, mesmo assim buscavam realizar atividades que propiciassem o desenvolvimento da criticidade, autonomia e argumentação em seus alunos. Utilizando para isto, diferentes espaços. Acredita-se que há muito ainda a estudar sobre a AC e os ENF, pois entende-se que são fundamentais para ajudar as crianças e adolescentes a tornarem-se cada vez mais críticos, argumentativos e fazendo sempre o melhor para si mesmos e para o próximo.

Palavras-chave: Alfabetização científica. Espaços não formais. Professores.

\section{ABSTRACT}

The present research made it possible to discuss two themes that, through scientific divulgation, showed a focus of studies in the field of Education and Education, Scientific Literacy (AC) and Non-formal Teaching and Learning Spaces (ENF). The objective of this study is to analyze how Early Childhood, Early Years and Final Years teachers of the Elementary School use the ENF seeking the AC of their students in four public schools in the state of Rio Grande do Sul / Brazil. The methodological procedures involved descriptive and exploratory qualitative research using the inductive method. The subjects investigated were eight teachers - two from Early Childhood Education, three from the Early Years and three Final Years from Elementary School, from four schools in the municipality of $X X$. The data collection was contemplated in 2018 and counted with semi-structured interviews, observations recorded in the field diary and conversation round. The data were analyzed by performing Discursive Textual Analysis, generating emerging categories. The teachers demonstrated that they did not know the terms AC and ENF, nevertheless they sought to carry out activities that fostered the development of criticality, autonomy and argumentation in their students. Using different spaces for this. It is believed that there is much still to be done about AC and ENF, since it is understood to be fundamental to help children and adolescents become increasingly critical, argumentative and doing their best for themselves and for the next.

Keywords: Scientific literacy. Non-formal spaces. Teachers.

1 Universidade do Vale do Taquari - Univates 


\section{INTRODUÇÃO}

O presente escrito, é decorrente de um recorte da pesquisa desenvolvida na dissertação da primeira autora no Mestrado XX, que transcorre pelas investigações da Alfabetização Científica (AC) e Espaços não Formais de Ensino e de Aprendizagem (ENF). Muitas definições são atribuídas ao conceito de AC, para isso, define-se nesta pesquisa como um "entendimento de mundo" e para os ENF como espaços de interações onde ocorrem o ensino e a aprendizagem. Lorenzetti e Delizoicov (2001, p. 49) afirmam “[...] que os assuntos científicos sejam cuidadosamente apresentados, discutidos, compreendendo seus significados e aplicados para o entendimento do mundo". Neste sentido, o entendimento de mundo vem ao encontro da ideia de que o aluno possa entender o mundo a qual vive, sua realidade e que venha a compreender, que os conteúdos que está aprendendo na escola tem relação com sua vida. Há muitas pessoas que passam anos na escola e saem sem este entendimento de mundo, isto é, sem compreenderem por exemplo, que os alimentos possuem rótulos que fornecem a composição do alimento, outro exemplo simples que muitas pessoas não sabem explicar é porquê os médicos receitam medicamentos para serem tomados por exemplo de oito em oito horas, simplesmente tomam, não tendo explicações ou ficando com falas de seno comum.

Uma pessoa alfabetizada cientificamente, não constrói o entendimento de mundo de maneira rápida, mas sim, ao longo de um processo, é uma construção de saberes, entendimentos e relações. Isso se explica, por que muitos pesquisadores já sugerem a AC na Educação Infantil, para assim garantir um processo contínuo desta construção, como sugere Demo (2010), que afirma que a AC deveria iniciar nos primeiros anos da criança na escola, para familiarizarem-se com o mundo científico. Mas para que a AC ocorra é necessário que os professores entendam a epistemologia, conceitos, atividades que possibilitam o seu desenvolvimento e também saibam quais indicadores se apresentam e evidenciam a presença da AC nos educandos.

Uma possibilidade de aprofundar e desenvolver a AC é utilizando os espaços não formais, em ambientes externos da sala de aula. Sejam eles espaços não formais institucionalizados e não institucionalizados. Para Jacobucci (2008) correspondem aos institucionalizados os museus, Centro de Ciências, zoológico, instituições que oferecem monitores, guias e placas explicativas do lugar, o professor tem todo o aporte técnico para a visitação e exploração. Os espaços não institucionalizados, como as praças, ruas, parques, necessitam que o professor desenvolva toda a prática pedagógica.

Acredita-se que o ensino e a aprendizagem ocorram em todos os espaços, mas a preocupação é que não aconteça apenas na sala de aula, mas sim em outros ambientes também, onde os alunos possam perceber que o ensino que é lhes proposto tem total relação com seus cotidianos, suas realidades, que possam ver as potencialidades da sua comunidade e também os problemas que possui. Gohn (2014, p. 02) destaca que a aprendizagem em ambiente não formal "implica em participar do amplo debate epistemológico sobre a produção de conhecimento no mundo, contemporâneo”. Isso somente irá acontecer se os alunos puderem vivenciar na prática estes fatos, realidades e se perceber como sujeito responsável e ativo no espaço no qual vive.

A AC, tem a intencionalidade de tornar o aluno mais crítico, que consiga resolver os problemas que surgir, que argumentem e saibam elaborar hipóteses. Isto é potencializado por espaços fora dos muros da escola, que além disso, possibilitam e fomentam as relações entre aluno-aluno, professor-aluno e ambiente-professor-aluno.

A temática AC teve origem em meados da década dos anos 50, com um livro denominado "Science Literacy: Its Meaning for American Schools2 ”, lançado no ano de 1958 nos Estados Unidos através de Paul Hurd, sendo ele uma das grandes referências para os estudos da AC. Se faz necessário destacar que a AC surge com o propósito de formar cientistas, alunos com mais conhecimentos sobre a Ciência, visto que, aparece logo após a segunda guerra mundial (SASSERON, 2011).

2 Tradução para a Língua Portuguesa: “Alfabetização Científica: Seu Significado para as Escolas Americanas” 
No decorrer dos anos, a AC vem obtendo destaque na área educacional, sendo discutida como uma alternativa de melhorar o ensino nas escolas, fazendo com que o aluno se perceba e entenda o meio no qual vive e que consiga interferir e mudar para melhor sua realidade e também da sociedade. Chassot (2004, p. 67) salienta que "na vida das mulheres e dos homens, há a necessidade de uma participação na sociedade (e uma participação com transformações). [...], sejam instrumentos que permitam o exercício de uma cidadania plena, para que essa participação seja de forma ativa e crítica nas tomadas de decisões” A esse respeito, Dutra, Oliveira e Del Pino (2017, p. 58) afirmam: "entendemos que a alfabetização científica representa um conjunto de conhecimentos científicos e tecnológicos que facilitariam aos homens e mulheres fazer uma leitura do mundo onde vivem, para assim compreendê-lo e transformá-lo".

Em 2006, Lemke, em seu artigo "Investigar para el futuro de la educación científica: nuevas formas de aprender, nuevas formas de vivir”, destaca a importância de repensar o ensino de Ciências, considerando os níveis de ensino e especificidades dos alunos. Cada nível de ensino tem suas peculiaridades, seu tempo de aprendizagem, por esta razão a AC deve ser inserida logo na Educação Infantil pois os professores terão bastante tempo para desenvolver atividades que propulsionem o espírito investigativo, com atividades capazes de provocar a curiosidade e também na solução e resolução de problemas. Sasseron e Carvalho (2008, p. 336) afirmam que:

[...] partimos da premissa de que é necessário iniciar o processo de Alfabetização Científica desde as primeiras séries da escolarização, permitindo que os alunos trabalhem ativamente no processo de construção do conhecimento e debate de ideias que afligem sua realidade.

Pensar a AC desde a Educação Infantil, até o Ensino Médio e Superior é extremamente importante pois há muitas pessoas que não chegam no nível superior, o ideal é que possam ter uma educação básica de qualidade, que desenvolvam habilidades como argumentar, resolver problemas, a criticidade, trabalho em grupo, autonomia. Neste sentido, a AC é importante na etapa da Educação Básica, pois quem não tiver continuidade em seus estudos poderá usar no decorrer de sua vida, já aqueles que continuarem terão um olhar mais crítico nas disciplinas, não aceitarão tudo que lhes são impostos, conseguindo argumentar e expor suas opiniões. Demo (2010) também diz que, algumas vezes, a escola limita e atrapalha a proposta de um ensino voltado para a pesquisa e acaba objetivando unicamente as disciplinas, lembrando que a AC vai além dos conteúdos.

Há muitas questões a serem pensadas e repensadas na sociedade em geral, como a educação, política, segurança, saúde, neste sentido remete novamente que uma pessoa alfabetizada cientificamente terá a capacidade de achar soluções e principalmente colocar em prática. Muitos trabalhos científicos remetem que AC desenvolva a criticidade, mas é imprescindível que estes alunos também reajam frente a questões que surgirem, não ficado somente no discurso. Oportunizar experiências em outros espaços torna-se uma possibilidade de ensinar e aprender de maneira diferente.

Para isso, a proposta de pesquisa deste recorte da dissertação de mestrado perpassou pela investigação de percepções e atividades desenvolvidas por oito professoras de quatro escolas públicas, do município de XX/RS, objetivou-se: a) verificar as concepções dos professores envolvidos na pesquisa sobre os temas: AC e ENF de Ensino e de Aprendizagem; b) Investigar como os professores organizam e desenvolvem suas aulas no cotidiano de suas práticas pedagógicas, considerando a Alfabetização Científica de seus alunos em Espaços não Formais de Ensino e de Aprendizagem e c) Identificar as dificuldades e motivações dos professores ao realizar suas aulas em Espaços não Formais de Ensino e de Aprendizagem visando a Alfabetização Científica dos alunos. 


\section{CAMINHO METODOLÓGICO}

Para a realização desta pesquisa, optou-se pela pesquisa descritiva e exploratória pelo fato de esclarecer/ modificar/desenvolver conceitos e ideias, para obter conhecimento e compreensão e também por descrever os fatos e fenômenos de determinadas realidades. Apresenta abordagem qualitativa, pois visa a qualidade dos fatos e fenômenos, como justifica Martins e Ramos (2013, p. 123-124). Para estes autores, este tipo de pesquisa atua com base nos "significados, razões, desejos, crenças, valores, atitudes e outras características subjetivas próprias do ser humano que não podem ser limitadas a variáveis numéricas”. O lócus de pesquisa foram quatro escolas públicas da cidade de XX, contou com a participação de oito professoras distribuídas entre a Educação Infantil, Anos Iniciais ( $1^{\mathrm{a}}$ a $6^{\mathrm{a}}$ série) e Anos Finais ( $7^{\mathrm{a}}$ a $9^{\mathrm{a}}$ série) do Ensino Fundamental. As análises se procederam através da Análise Textual Discursiva (ATD) proposta por Moraes e Galiazzi (2013).

Para o desenvolvimento desta proposta, primeiramente obtivemos a autorização da Secretaria de Educação do município de XX, apresentamos o projeto e seus desdobramentos. Posteriormente, conversamos com as professoras das escolas sugeridas pela secretária da Educação, após apresentar a proposta, elas analisaram e assinaram o Termo de Consentimento Livre e Esclarecido (TCLE) aceitando participar da pesquisa.

Para a coleta das informações foram utilizados os seguintes instrumentos: entrevistas semiestruturadas gravadas, observação da prática pedagógica das professoras e uma roda de conversa. Inicialmente ocorreram as entrevistas semiestruturadas com perguntas abertas que possibilitou um espaço para as professoras colocarem suas percepções, durante a entrevista um gravador ficou ligado e registrou o diálogo para posterior transcrição das falas. No segundo momento de pesquisa, foram realizadas as observações da prática das oito professoras sendo registrado através de fotos com o uso do celular e com anotações no diário de campo pelas pesquisadoras

A última etapa desta proposta contou com uma roda de conversa com três das professoras, que se dispuseram para este momento. Esta atividade buscou conhecer as motivações e dificuldades encontradas pelas professoras para desenvolver as atividades que envolvam a AC em ENF. Nesta roda de conversa foi utilizado um gravador e posteriormente foram realizadas as transcrições. Para preservação da identidade das professoras durante as análises, estas foram identificadas como Professora 1 (P.1), (P.2) ... (P.8).

\section{RESULTADOS E DISCUSSÃO}

Os resultados e discussões, foram organizados em três momentos, correspondendo aos três objetivos específicos propostos a fim de manter uma sequência e, ao mesmo tempo, apresentar mais detalhes acerca dos dados encontrados, que dialogam com autores da área pesquisada. Assim, para verificar as concepções dos professores sobre os temas desta pesquisa emergiram da fala das professoras durante a entrevista duas categorias:

Categoria 1: Desconhecimento da temática AC e atividades que possibilitam o seu desenvolvimento.

Categoria 2: Desconhecimento do termo ENF e locais explorados durante o ano com as crianças.

A primeira categoria, surgiu a partir do desconhecimento do termo pelas professoras que demostraram dificuldades para expressar o que significava a AC, evidenciando nas seguintes falas:

Não que eu me lembre, por este nome não (P. 2)

Muito pouco. Em uma das reuniões da escola. Foi explanado um pouquinho sobre isso (P. 6)

Não. Como eu tenho os bebês pra nós fica assim... é uma realidade um pouco mais distante né?! Pra mim na verdade é uma palavra nova (P. 7) 
É evidente que desconhecem a epistemologia da palavra, sendo que durante as entrevistas notou-se um desconforto por parte das professoras, sendo as respostas elaboradas de maneiras objetivas, principalmente pelo fato da incompreensão da AC.

A fala da docente 7, nos apresenta que, pelo fato de trabalhar com os bebês, a AC fica distante da sua realidade, ou seja, da realidade dessa faixa etária. Porém, há muitos estudos que vêm defendendo a ideia da AC na Educação Infantil. Conforme Almeida e Téran (2013, p. 06), “as concepções trazidas pela Alfabetização Científica à Educação Infantil podem promover a formação mais integral do cidadão, um ser cada vez mais pensante e atuante, responsável pelos destinos da sociedade”. É necessário e importante pensar a AC nos primeiros anos da criança na escola.

Apesar de não saberem o que a AC propõe, nota-se pela fala delas, que buscam aproximações com atividades importantes para desenvolver a AC. Nas falas destacaram algumas das atividades:

Normalmente no início do ano eu lanço pra eles o que eles tem interesse, daí eu faço uma explosão de ideias, daí a gente faz um grande mapa conceitual juntos, a gente vai vendo o que eles querem trabaIhar e a partir dali, trabalhar o meu plano de trabalho para aquele trimestre [...] tudo que é novo o aluno gosta. Tudo o que parte deles, eles gostam mais do que o que a gente propõe (P. 1)

Então a gente costuma levar muito eles para o laboratório “ah a gente vai pesquisar tal artista” (P. 2)

As atividades são realizadas através de experimentos, observações, saídas a campo, visitas, entrevistas, relatos, vídeos, palestras, pesquisas. São atividades que nos dão oportunidade de trabalhar a partir das curiosidades necessidades dos alunos. Além disso, são situações que levam a uma compreensão mais real e permanente, afinal é vivenciada. Acredito que é dessa forma que se constroem aprendizagens importantes para a vida (P. 4)

As professoras citaram como alternativas o uso do laboratório, construção de mapa conceitual, vídeos, observações, saídas de campo ... Ao final da fala da professora 4, ela menciona: "além disso, são situações que levam a uma compreensão mais real e permanente, afinal é vivenciada. Acredito que é dessa forma que se constroem aprendizagens importantes para a vida".

Essa fala revela que a professora compreende o quão importante é possibilitar um ensino mais dinâmico, que tenha significado e sentido para a vida. Mesmo não sabendo dizer sobre as definições de AC, já é evidente que ocorre o processo. Portanto, retomo a ideia de que

[...] a Alfabetização Científica é uma das prioridades do Ensino de Ciências nos anos iniciais do Ensino Fundamental, pois pode contribuir para uma leitura e interpretação de mundo que favoreça posicionamentos e tomadas de decisão, de modo crítico e criativo, em questões que envolvam nós, os outros e o ambiente (BRASIL, 2015, p. 7).

Assim, destaca-se a relevância levar a AC para os pequenos, potencializado um ensino mais significativo, fazendo uma leitura de mundo. Para tanto, observamos que além de conhecimento dos termos, os professores precisam buscar desenvolver atividades potentes para alfabetizar cientificamente seus alunos.

Quando mencionado para as professoras sobre os ENF, percebeu-se que era mais “entendível” por parte delas, porém algumas confusões quando se referiam a espaços formais e não formais, surgindo a categoria 2 "familiarização e desconhecimento referente ao termo Espaços não Formais pelas professoras e locais explorados durante o ano com as crianças". 
Sim e utilizo. Trabalho muito fora da sala. Ainda mais no pátio (P. 2)

Uma visita no corredor ou até o banheiro, a cozinha, tudo são espaços não formais, pracinha são espaços não formais, passeios... é maravilhoso quando se consegue fazer, visitações, exposições, então, é maravilhoso isso. Se tu consegue botar no teu planejamento então acredito que seja isso. Formal mesmo é a sala de aula (P. 3)

Sim, são todos os espaços que estão além dos muros da escola, da sala de aula. São atividades que complementam os estudos realizados. Várias são as maneiras utilizadas: vivências, observações, visitas (P. 4)

São outros espaços que não são o da sala de aula, usados para investigação e o desenvolvimento da aprendizagem. Ricas para a aprendizagem dos alunos. Sempre contribuíram e complementaram as temáticas de estudo (P. 5)

Ao meu ver, em uma escola, geralmente, pensam a sala de aula como um espaço formal, o primeiro. Porém, todos os espaços dentro de uma instituição, assim como fora a gente utiliza também, esses espaços externos ao redor da escola, são alfabetizadores. [...] Todos os espaços considero espaços não formais (P.6)

Verificando as respostas, pode-se perceber que algumas professoras entendem que os ENF são os espaços fora da escola, porém outras denominam como ENF o pátio, a pracinha, banheiro, o laboratório, a cozinha. Assim, realizam suas atividades em espaços formais, pensando que são ENF, o que mostra os desentendimentos ao definir o que corresponde cada espaço.

Muitos autores já vêm pensando na relação entre a AC e os ENF, um destes trabalhos é de Lorenzetti, Delizoicov (2001, p. 51) onde afirmam que "visitas a museus; zoológicos, indústrias, estações de tratamento de águas e demais órgãos públicos; organização e participação em saídas a campo e feiras de Ciências”, são exemplos de ENF, ou seja, são espaços possíveis para serem utilizados pelos docentes. Seguindo a ideia dos espaços, Lorenzetti e Delizoicov (2001, p. 51) também afirmam:

Se a escola não pode proporcionar todas as informações científicas que os cidadãos necessitam, deverá, ao longo da escolarização, propiciar iniciativas para que os alunos saibam como e onde buscar os conhecimentos que necessitam para a sua vida diária. Os espaços não formais compreendidos como museu, zoológico, parques, fábricas, alguns programas de televisão, a Internet, entre outros.

Há muitas possibilidades de ENF, cabe ao professor conduzir o processo e explorar estes espaços. Na fala da professora 6, destaca que somente a sala é um espaço formal, sendo os outros espaços da escola como não formais. ENF como destacado por Lorenzetti e Delizoicov (2001), são os espaços externos da escola... fica evidente que esta professora possui um desentendimento de conceitos.

O segundo objetivo específico deste estudo se propôs a "investigar como os professores organizam e desenvolvem suas aulas no cotidiano de suas práticas pedagógicas, considerando a AC de seus alunos em ENFormais de Ensino e de Aprendizagem". A fim de contemplar este objetivo, foram realizadas observações de aulas das oito professoras com o uso do diário de campo, foi escolhido uma aula observada para discussão neste trabalho.

A aula escolhida foi do $3^{\circ}$ ano do Ensino Fundamental. A professora (P6) elaborou uma atividade de multiplicação matemática. O nome da atividade foi “observando as multiplicações: o que vejo de multiplicação na minha escola”, nesta atividade as crianças precisaram observar os objetos e estruturas físicas da escola e fazer a representação em forma de desenho e após elaborar os próprios cálculos. Os alunos percorreram por vários espaços da escola, como a área aberta (FIGURA 1), área fechada (FIGURA 2), podendo escolher se gostaria de trabalhar em grupos ou individualmente, os cálculos eram pensados e elaborados pelas próprias crianças. A professora ficava todo o tempo circulando e observando os cálculos, quando percebia que a conta estava errada não dava a resposta, mas sim, pedia para o aluno observar o que havia desenhado e fazer o processo novamente, onde a própria criança percebia o erro. 
Figura 1 - Crianças desenvolvendo suas atividades no pátio da escola.

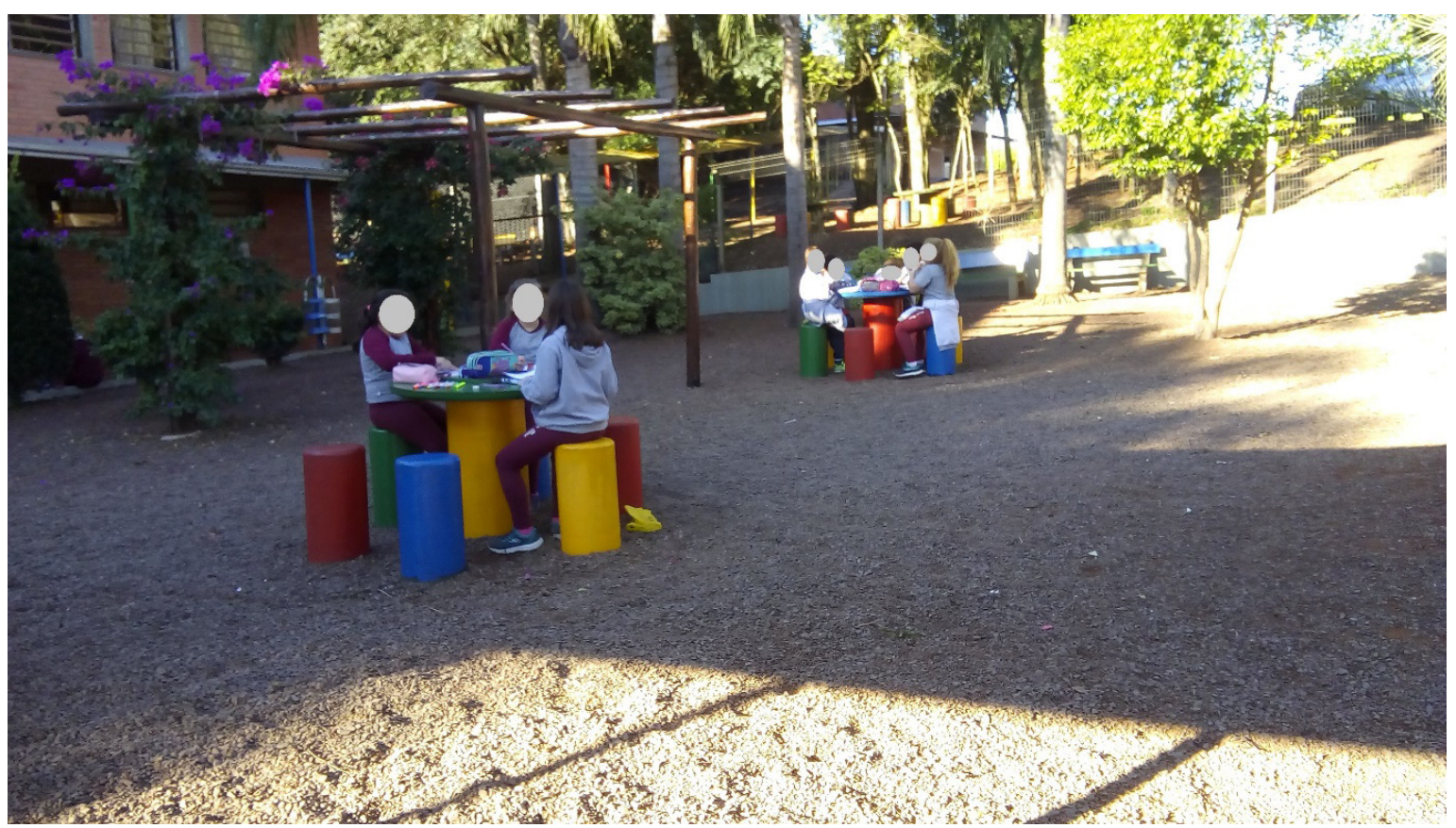

Fonte: das autoras, 2018.

Figura 2 - Crianças explorando as dependências da escola.

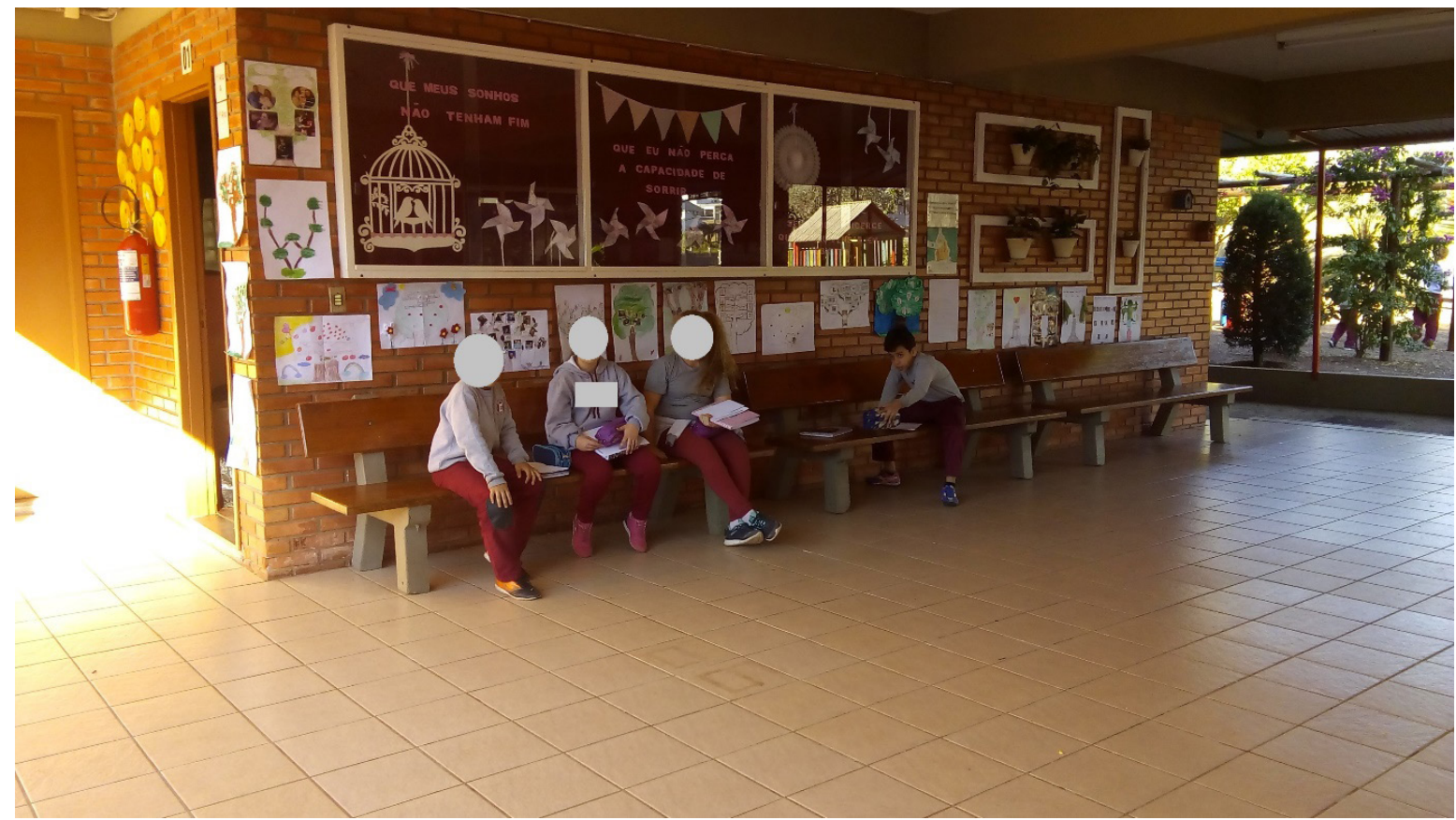

Fonte: das autoras, 2018 
A professora desta turma de alunos havia comentado que somente a sala é um espaço formal e ficou evidente que realmente considerava o pátio da escola como um ENF, pois realizou sua aula neste espaço. Almeida e Oliveira (2014) dizem que a utilização de ENF, no processo de ensino e aprendizagem, apresenta a intenção de preparar o sujeito para enfrentar os desafios dos tempos modernos enquanto cumpre seu papel para a prática da cidadania, indo além do conteúdo.

É importante salientar que os espaços da escola são ótimos para desenvolver atividades, porém acredita-se que existem outros espaços para atribuir um ensino significativo aos alunos fora das dependências da escola, ainda mais se pensando na AC no intuito de aprofundar os conhecimentos e estar ligada a realidade dos alunos, mostrando-lhes que há muito a descobrir e observar nas trilhas ecológicas, nos museus, jardins botânicos, nas fábricas e indústrias. "Só assim é possível formar sujeitos conhecedores da Ciência, socialmente responsáveis e reflexivos, capazes de serem agentes de transformação no meio em que estão inseridos” (ARAÚJO et al., 2014, p. 25).

No terceiro objetivo intitulado "identificar as dificuldades e motivações dos professores ao realizar suas aulas em Espaços não Formais de Ensino e de Aprendizagem visando a Alfabetização Científica dos alunos”, surgiram três categorias emergentes denominadas:

Categoria 1: Limitações que perpassaram pelo Ensino Superior.

Categoria 2: Marcas que ficaram.

Categoria 3: Mudança a partir da própria práxis.

As categorias emergiram a partir da roda de conversa composta pelas três professoras (P.1), (P.4) e (P.5). A primeira categoria "limitações que perpassaram pelo Ensino Superior", destacam a maneira que que foi atribuído as aulas no Ensino Superior:

A gente ia no laboratório, fazia observação, análise, pesquisa na bibliografia e a gente então produzia digamos assim materiais que pudessem nos dar um suporte pra gente trabalhar com a parte mais da pesquisa, em cima de alguns assuntos e de algumas coisas que a gente vivenciava, tanto na prática quanto na teoria, que eu lembro assim, botânica, zoologia, a própria Biologia (...). E matemática que eu lembro assim a gente tinha algumas disciplinas como geometria, modelagem matemática em que a gente também explorava o material, experenciava, pesquisava alguma coisa sobre aquele conteúdo, apresentava trabaIhos enfim, pra entender um pouquinho da matemática, no cotidiano, no dia-a-dia para depois propor e trabalhar com alunos (P. 5)

Não. A gente até fazia algumas pesquisas científicas, tinha saídas de estudos, bem ele dava um roteiro pra gente seguir, a gente saia numa viagem onde a gente tinha que observar, fazer a comparação do que a gente tinha em sala de aula aprendido, e depois fazer um relatório, pegar a parte de fundamentação teórica, enfim, fazer um link (P.1)

Pode-se verificar, nas respostas, que houve, no Ensino Superior, momentos que se aproximavam da investigação, das pesquisas, mas, evidentemente, não era trabalhado de forma aprofundada. Da mesma forma, muitos professores desenvolvem, com seus alunos, pesquisas superficiais, não potencializando um ensino com AC. Demo (2010) destaca que é importante que a criança passe pelos processos de iniciação científica, mas, através desta discussão, nota-se que há necessidade de o Ensino Superior desenvolver melhor o ensino pela pesquisa.

Cabe destacar a importância de cada vez mais a AC ser trabalhada e desenvolvida no Ensino Superior e assegurar que chegue da melhor forma às Instituições de Nível Básico. Monteiro e Teixeira (2004, p. 23) enfatizam que não é meramente oferecer inovação, como uma receita aos professores, pois, "por mais virtuosa que possa ser, atividade nenhuma se impõe por si só. Ela só ganha significado mediante a maneira do professor incorporá-la à sua prática cotidiana”. 
Na categoria 2, denominada "marcas que ficaram” emergiu pelas lembranças que as professoras destacaram durante a roda de conversa, marcas que permanecem do Ensino Superior que perpassaram, algumas das falas que fica evidente as lembranças:

Eu vejo a minha... eu lembro da minha faculdade muito conteudista assim, era polígrafo pra gente ler, exercício pra fazer, leitura... eu não vejo essa parte de pesquisa, a gente lia um polígrafo em grupos, discutia e tinha que fazer uma apresentação. Nunca teve... (P. 1)

Não foi ensinado como trabalhar a pesquisa com alunos (P.4)

Nunca, a gente nunca teve assim algum tipo de orientação, ou fundamentação, algum autor, que eu lembre de graduação não (P. 5)

Esta categoria é importante, pois um ensino voltado para a AC é o oposto do que as professoras vivenciaram em sua vida acadêmica. Cachapuz et al. (2005, p. 10) ressaltam que "para uma renovação no Ensino de Ciências precisamos não só de uma renovação epistemológica dos professores, mas que essa venha acompanhada por uma renovação didático-metodológica de suas aulas”. Porém, para os docentes do Ensino Fundamental conseguirem pensar e realizar a proposta voltada à AC, é necessário que na sua formação ela seja estudada/apresentada e, principalmente, que seja demonstrada na prática de alternativas investigativas. É difícil trabalhar com uma abordagem sem conhecê-la de forma mais aprofundada ou, ainda pior, desconhecendo-a.

A partir da análise dos dados, mais uma categoria emergiu “mudança a partir da própria práxis”, uma vez que ficou saliente, nas falas das professoras, que as atividades que elas propõem aos seus alunos (Educação Infantil, Anos Iniciais e Anos Finais do Ensino Fundamental) são fruto de sua dedicação e de estudos feitos nas instituições em que atuam. Destacaram que é nas escolas que ocorrem as formações, em consequência dos grupos de estudos. Assim, pode-se afirmar que houve lacunas durante a formação, que poderia ter sido mais aproveitada.

A AC vem ganhando força a partir do ano de 2000, a partir de trabalhos científicos que foram publicados. Acredita-se que as novas gerações passarão pela experiência e assim a AC fará parte da vida de muitas pessoas. Seguem as falas das professoras:

Eu posso falar da minha formação profissional, em formações que a gente fez enquanto tá na função de ser professora e aí sim a gente trabalhou com livros do Pedro Demo e eu acho que foi "o que é pesquisa?" Que foi um dos livros que eu lembro que a gente trabalhou aqui, alguma coisa relacionada a projetos de trabalho do Hernandes (P. 5)

E a gente buscando por conta própria, pela necessidade que a gente sente no trabalho (P. 4)

Até porque teve uma época assim que veio com tudo o trabalho por projetos, né? Do Hernandes. Então assim, a gente teve palestras com pessoas que vinham aqui nos falar sobre, então na realidade a gente foi buscar algo em cima de pesquisa e que é: como trabalhar com a pesquisa, com as crianças, mas por conta própria. Em função do grupo da escola que tinha um desejo de aprender (P..5)

Eu acho que é bom, no entanto sempre tem os empecilhos que tu precisa por exemplo no transporte pra fazer uma saída dependendo o lugar que tu vai, tu precisa de um acesso à internet, tu precisa... e que às vezes a gente não tem, toda nossa... pra fazer uma pesquisa... É, precisa pra fazer alguma coisa... assim, eu esse ano tô trabalhando muito pouco com pesquisa, porque nossos alunos em casa tem pouco material para pesquisa e nós estamos sem laboratório de informática, então algumas coisas que a gente traz pra sala de aula, mas um trabalho efetivo de pesquisa como eu gosto de fazer, não tenho conseguido fazer esse ano, para ser bem sincera (P. 4)

E muitas vezes até que a gente não esteja trabalhando, mas pra eles terem o contato e ampliar a visão do mundo deles e causar a curiosidade, e fazer com que eles vejam bom (P. 5) 
As professoras também mencionam, em suas falas, a falta de fundamentações teóricas. Infelizmente, sem uma abordagem fundamentada, a prática fica muitas vezes descontextualizada e pouco explorada. É preciso um ensino prático e também teórico, pois ambos estão imbricados e não é interessante abordar apenas um deles. Para Dutra, Oliveira e Del Pino (2017, p. 60):

É imprescindível a formação de professores voltada à alfabetização científica e tecnológica, bem como inserir a pesquisa nesse processo de formação. O professor pesquisador é capaz de ultrapassar limites impostos pela concepção da escola tradicional.

Durante a roda de conversa, surgiram algumas das limitações para realizar as aulas em ENF. Nas falas das professoras, elas citam as seguintes dificuldades que enfrentam no cotidiano: as famílias, em geral, são humildes, não conseguindo pagar o deslocamento das crianças quando há saídas de campo; o transporte, quando necessário, é muito disputado; a falta de profissionais para acompanhar durante as saídas; as autorizações que nem sempre são assinadas pelas famílias; o número expressivo de alunos na turma; a idade das crianças. Esses indícios aparecem na fala da professora 4. Mas, apesar de tantos impedimentos, não desistem e fazem tudo que está ao alcance de cada uma e da escola.

\section{CONSIDERAÇÕES FINAIS}

Pode-se observar neste estudo que as professoras não compreendiam o significado do termo AC, tendo dificuldades de expor suas ideias e sentiam-se desconfortáveis durante a fala sobre AC. Da mesma forma que não possuíam clareza acerca da diferença entre espaços formais, informais e não formais, confundindo-se. As professoras trabalhavam a partir das curiosidades das crianças, citando algumas atividades que realizavam durante do ano, como saídas a campo, aulas em laboratório, palestras, vídeos, entre outras. Observou-se que as professoras em nenhum momento das aulas davam as respostas prontas para as atividades desenvolvidas, mas sim instigavam seus alunos a pensar e refletir sobre as atividades propostas.

Observamos que as professoras participantes deste estudo apresentaram limitações em relação às suas formações iniciais, destacando que o ensino poderia ter sido mais explorado, com leituras fundamentadas, com mais investigações e que melhor auxiliasse a entender como trabalhar estes aspectos na sala de aula com crianças.

Para contornar os desafios encontrados nas aulas, destacaram que foi preciso ressignificar a própria prática e ir atrás de estudos, citando a escola como o espaço para os estudos e para as formações continuadas. Percebendo as suas limitações decorrentes do Ensino Superior, elas evidenciaram que mudaram suas práticas e potencializaram um fazer diferente, de suas experiências do obtidas, para assim garantir um ensino de mais qualidade e eficaz.

Percebe-se que ainda há necessidade de investigações acerca da AC e do ENF, visto que ainda são conceitos novos e há um desentendimento em relação aos mesmos. Esta pesquisa não teve a intenção de trazer verdades, mas sim, novas possibilidades de trabalhar no cotidiano escolar de maneira diferente e significante ao aluno, um ensino capaz de aproximar seus ensinamentos e a realidade ao qual o aluno vive. 


\section{REFERÊNCIAS}

ALMEIDA, Maria SaleteBortholazzi; OLIVEIRA, Silmara Sartoreto de. Educaçãonão formal, informal eformal do conhecimento científico nos diferentes espaços de ensino e aprendizagem. In. Os desafios da escola pública paranaense na perspectiva do professor: Produções Didático-Pedagógicas. 2014. Versão Online Disponível em: <http://www.diaadiaeducacao.pr.gov.br/portals/ cadernospde/pdebusca/producoes_pde/2014_uel_bio_pdp_maria_salete_bortholazzi_almeida.pdf > . Acesso em: 17 dez. 2018.

ALMEIDA, Erick Rodrigo Santos; TERÁN, Fachín. A Alfabetização científica na educação infantil: possibilidades de integração. In: conferência da associação latinoamericana de investigação no ensino de Ciências, 2013, Manaus, Anais..., Manaus: 22 a 25 de out. 2013.

ARAÚJO, Ione dos Santos Canabarro; CHESINI, Talita Sganderla; FLLHO, João Bernardes da Rocha. Alfabetização científica concepções de educadores. Revista Contexto \& Educação, Unijuí, ano 29, n. 24, p. 4-26, set.dez. 2014.

BRASIL. Pacto Nacional pela Alfabetização na Idade Certa. Ciências da Natureza no Ciclo de Alfabetização. Caderno 08. Brasilia: MEC, SEB, 2015.

CACHAPUZ, António; et al. Anecessária renovação do ensino das Ciências. São Paulo: Cortez, 2005.

CHASSOT, Áticco. Para que(m) é útil o ensino? Alternativas para um ensino (de Química) mais crítico. 2. ed. Canoas: Ed. da Ulbra, 2004.

DEMO, Pedro. Educação e alfabetização científica. São Paulo: Papirus, 2010

DUTRA, GildeteElias; OLIVEIRA, Eniz Conceição; DEL PINO; JoséClaudio. Alfabetização científica etecnológica na formação do cidadão. Signos, Lajeado, a. 38, n. 2, p. 56-62, 2017.

GHON, Maria da Glória. Educação não formal, aprendizagens e saberes em processos participativos. Revista Investigar em Educação. II a série, n. 1, 2014.

JACOBUCCI, Daniela Franco Carvalho. Contribuições dos espaços não-formais de educação para a formação da cultura científica. Em Extensão. Uberlândia, v. 7, p. 55-66, 2008.

LEMKE, Jay. Investigar para el futuro de la educación científica: nuevas formas de aprender, nuevas formas de vivir. Enseñanza de las Ciencias, v. 24, n.1, p. 5-12, 2006.

LORENZETTI, Leonir; DELIZOICOV, Demétrio. Alfabetização Científica no contexto das séries iniciais. Ensaio, Pesquisa em Educação em Ciências. Belo Horizonte, v. 3, n. 1, p. 45-61, jun. 2001.

MARTINS, Ronei Ximenes; RAMOS, Rosana. Metodologia de pesquisa: guia de estudos. p. 8-21, Lavras: UFLA, 2013.

MONTEIRO, Marco Aurélio Alvarenga. TEIXEIRA, Odete Pacubi Baierl. O ensino de física nas séries iniciais do ensino fundamental: um estudo das influências das experiências docentes em sua prática em sala de aula. Investigações em Ensino de Ciências. Porto Alegre, v. 9, n. 01, 2004.

MORAES, Roque; GALIAZZI, Maria do Carmo. Análise textual discursiva: processo construído de múltiplas faces. Ciência e Educação. São Paulo, v.12, n.1, p.117-128, 2006.

SASSERON, Lúcia Helena; CARVALHO, Anna Maria Pessoa de. Almejando a alfabetização científica no ensino fundamental: a proposição e a procura de indicadores do processo. Investigações em Ensino de Ciências. Porto Alegre, v. 13, n. 03, p. 333-352, 2008.

SASSERON, Lúcia Helena. Alfabetização científica: uma revisão bibliográfica. Investigações em Ensino de Ciências. Porto Alegre, v. 16, n.1, p. 59-77, 2011. 